\title{
Bilişim Çağında Bilginin Değişen Yüzü: İnfobezite Üzerine Kavramsal Bir İnceleme
}

\author{
Betül ERSÖZ1 (iD), Ümmü Gülsüm KAHRAMAN²*(D) \\ ${ }^{1}$ Gazi University, Rectorship, Ankara, Turkey \\ ${ }^{2}$ Asst. Prof. Dr., Burdur Mehmet Akif Ersoy University, Bucak Zeliha Tolunay School of Applied Technology \\ and Management, Department of Management Information Systems, Burdur, Turkey
}

Geliş Tarihi/Received: 11.08.2020

Kabul Tarihi/Accepted: 22.09.2020 Derleme Makalesi/Review Article

\section{ÖZET}

21. yüzyıla doğru teknolojinin hızla gelişmesi yeni bilgi kaynaklarının ortaya çıkmasını sağlayarak, bireylerin ihtiyaç duyduklarından daha fazla bilgiye erişmelerine olanak sağlamıştır. Bilişim çağı olarak nitelendirdiğimiz bu dönem, bilgiye olan açlığımızı fazlasıyla doyurmaya yetmiş, aşırı bilgi yüklemesi sebebiyle çeşitli kaynakların ortaya çıkmasına neden olmuştur. Teknolojinin gelişmesi ile ortaya çıkan önemli kavramların başında yer alan internet, günümüzde bireylerin günlük hayatlarının vazgeçilmez bir parçası olmuştur. İnternetin dijital dünyaya sunmuş olduğu olanaklar, bireyleri kontrol edilemeyen bir bilgi alışverişine sürükleyerek bilgi kaynaklarının dijital platformda yayılmasını sağlamış ve bilgi kirliliğinin oluşmasına sebep olmuştur. Bilgi kirliliğinin artmasıyla birlikte infobezite kavramı ortaya çıkmıştır. İnfobezite kavramı, bireylerin günlük hayatlarında alması gerekenden daha fazla bilgiye maruz kalmasını ve bilgi obezliğinin olumsuz etkilerini anlatmak için kullanılmaya başlamıştır. Bilişim çağında ortaya çıkan Web 2.0 teknolojileri ve akıllı telefonlar da bilginin değişik boyutlarına her an erişilmesini sağladığından adeta bilgi istilasının oluşumuna zemin hazırlamıştır. Yaşadığımız bu çağda bireylerin üzerindeki etkisi tartışılmaz olan infobezite kavramı bu açıdan önemlidir. İnfobezitenin görece yeni bir kavram olması ve yeterince çalışılmamış olması noktasından hareketle bu çalışmanın amacı, infobezite kavramının derinlemesine incelenip, infobezite kavramı hakkında çeşitli görüşler ve yapılmış araştırmalara yer vererek literatüre katkı sağlamaktır.

Anahtar kelimeler: Bilişim Çağı, Bilgi, Dijitalleşme, İnfobezite. 


\title{
The Changing Face of Information in The Age of Informatics: A Conceptual Study on Infobesity
}

\begin{abstract}
The rapid development of technology during the 21 st century enabled new information sources to emerge, allowing individuals to access more information than they needed. This period, which we describe as the information age, has been enough to over saturate our hunger for knowledge, and caused the emergence of various new technologies in order to manage the overloaded information. Internet, which is one of the important concepts emerging with the development of technology, has become an indispensable part of individuals daily lives today. The opportunities offered by the internet to the digital world have dragged individuals into an uncontrollable exchange of information, enabling the spread of information resources on the digital platform and causing information pollution. With the increase of information pollution, the concept of infobesity has emerged. The concept of infobesity has begun to be used to explain the exposure of individuals to more information than they should get in their daily lives and the negative effects of information obesity. Web 2.0 technologies and smart phones emerging in the information age have provided the access to different dimensions of the information at any time, thus paving the way for the formation of an information invasion. In this age, the existince infobesity, of which impact on individuals is indisputable, is important in this respect. The purpose of this study is to contribute to the literature by including various opinions and researches about the concept of infobesity, considering that the infobesity concept is a relatively new concept and not studied enough.
\end{abstract}

Keywords: Age of Informatics, Information, Digitalization, Infobesity.

\section{GİİŞ}

İnternet teknolojisinin gelişmesi ve dijitalleşmenin artmasına kadar olan sürede sadece yazılı kaynaklardan bilgiye erişim sağlanırken, günümüzde bilgi kaynaklarına erişim dijital dünyanının hayatımıza girmesiyle birlikte her geçen gün daha kolay hale gelmiştir. Teknolojinin sunduğu araçların gelişiminden önce bireyler, evlerinde bulunan ansiklopediler, dergiler ve gazeteler gibi bilgiye ulaşmayı sağlayan her türlü yazılı metin ile bilgiye erişimi sağlamaktaydı. Bireyler bu işlemleri uygularken istenilen bilgiye ancak birkaç kaynak inceleyerek ulaşabiliyordu. Dijitalleşme ile ortaya çıkan internet kavramı, bireylerin bilgiye hızlı bir şekilde erişmelerini sağlamıştır. İnterneti, dünya genelindeki milyonlarca bilgisayar ağını ve kurumsal bilgisayar sistemini TCP/IP protokolü ile birbirine bağlayan, dünya çapında 
yaygın olan ve sürekli büyüyen bir elektronik iletişim ağı olarak tanımlamak mümkündür (Geray,2002). Yer ve zamana bağlı olmadan bireyler arasında bağlantı kurulmasını ve eş zamanlı iletişim sağlayarak doğrudan geri bildirim alınmasını mümkün kılan internet, zaman içerisinde dünya geneline yayılmıştır (Korp,2006). Teknolojinin sunmuş olduğu dijital platformlar ile bilgi kaynaklarına erişim öyle bir boyuta ulaştı ki, artık bilgiye erişim saniyeler içerisinde gerçekleşmektedir. Bu duruma olanak sağlayan, e-kitaplar, e-dergiler, bloglar, wikiler, makaleler vb. gibi bilimsel kaynakların dijital platforma taşınması süreci daha da hızlandırmıştır. Bu durum bireylerin hayatlarında kolaylıklar sağlarken, beraberinde çeşitli sorunların da ortaya çıkarmasına zemin hazırlamıştır. Bilgiye erişimde çok fazla kaynak olmasının sonucu olarak bilgi kirliliği ortaya çıkmıştır. Bu durum bilgi obezliğine sebep olarak “infobezite" kavramının ortaya çıkmasına neden olmuştur. 1970 yılında ilk olarak Alvin Toffler (1970) tarafından yazılan "Future Shock" adlı kitapta "information overload" yani aşırı bilgi yüklemesi olarak tanımlanan kavram günümüzde "infobezite" olarak nitelendirilmektedir. Alvin Toffler kitabında geleceğin erken gelişinin getirdiği baş döndürücü yönelim bozukluğunun, yarının en önemli hastalığı olabileceğini söylemiştir. Ayrıca bilgi fazlalığının sonucu olarak karar verme ve bir durumu anlamada da bireylerin zorluk yaşayacağını dile getirmiştir. John Naisbitt (1982) ise infobeziteyle ilgili olarak, "Datada boğuluyoruz ama bilgiye açız” yorumunu yapmıştır. Bilgi bolluğunun yaşandığı küresel dünyada büyük verinin içerisinde öylesine gereksiz bilgilerle zaman harcanılmaktadır ki gerçek bilginin doğruluğu sorgulanmaktadır. Bu durumda bireyler doğru ve güvenilir bilgiye erişmek için daha fazla zaman harcanmaktadır. "Aşırı bilgi yüküyle ölüm” başlıklı makalesinde Paul Hemp bilgi üretme kapasitesinin bu bilgiyi en iyi şekilde kullanma yeteneğini geride bıraktığını ve aşırı bilgi yüklemesinin bu bozukluğunun bir belirtisi olduğunu, söylemiştir (Hemp,2009). Eppler ve Mengis (2004)'e göre, bilgi potansiyel olarak yararlı olsa da, alınan bir yardımdan ziyade bir engel haline geldiği zaman infobezite meydana gelmektedir. Özellikle, son yıllarda dünyanın her yerinde kullanılan e-posta, WhatsApp, Facebook ve YouTube gibi platformlar interaktif iletişim ortamı içerisinde çok büyük miktarlarda bilgi üretmektedir. Bu platformlarda üretilen bilgiler her geçen gün daha da artarak bilgi yığınına sebep olmaktadır. Öyle ki, bu durum kişilerin infobez olmasına ve kendi koşullarında gerçekten ihtiyaç duymadıkları bilgileri tüketmelerine sebep olmaktadır (Lewis, 2018). Aşırı bilgi birikiminin yol açtı̆̆ı karmaşıklık sonucunda çoğu kişi işine yarayan veya yaramayan her türlü bilgiyi tüketmeye başlamıştır. Özellikle, internet ve sosyal medyanın aşırı ve bilinçsiz kullanımı bilgi obezitesini tetiklemektedir (Johnson, 2012). Sosyal medya ve yeni iletişim teknolojileri, bireylerin sosyal bir varlık olmasından doğan bilme, öğrenme, merak etme, ilişki kurma, beğenilme, 


\section{Ersöz, B. \& Kahraman, $\ddot{U}$. G.}

düşüncelerini açıklama ve haberdar olma gibi ihtiyaçlarını doyururken aynı zamanda onları uyuşturabilmekte ve zihinlerinin obezleşmesine neden olabilmektedir (Katz vd., 1973).

Günümüzde Türkiye'de internetin girmediği ev yok denilecek kadar azdır. Bununla birlikte bireylerinde bilgiye ulaşmak için internet kaynağı kullanım oranları da artmıştır. "We Are Social vs HootSuite" tarafından 2019 yılı için yayınlanan Küresel Dijital Rapor'unda, Dünya'nın ve Türkiye'nin dijital alandaki konumuna yönelik bilgilere yer verilmiştir. Şekil 1'de Dünya'daki mobil abone sayısı, internet kullanıcıları ve sosyal medya kullanımı hakkında bilgiler yer almaktadır.

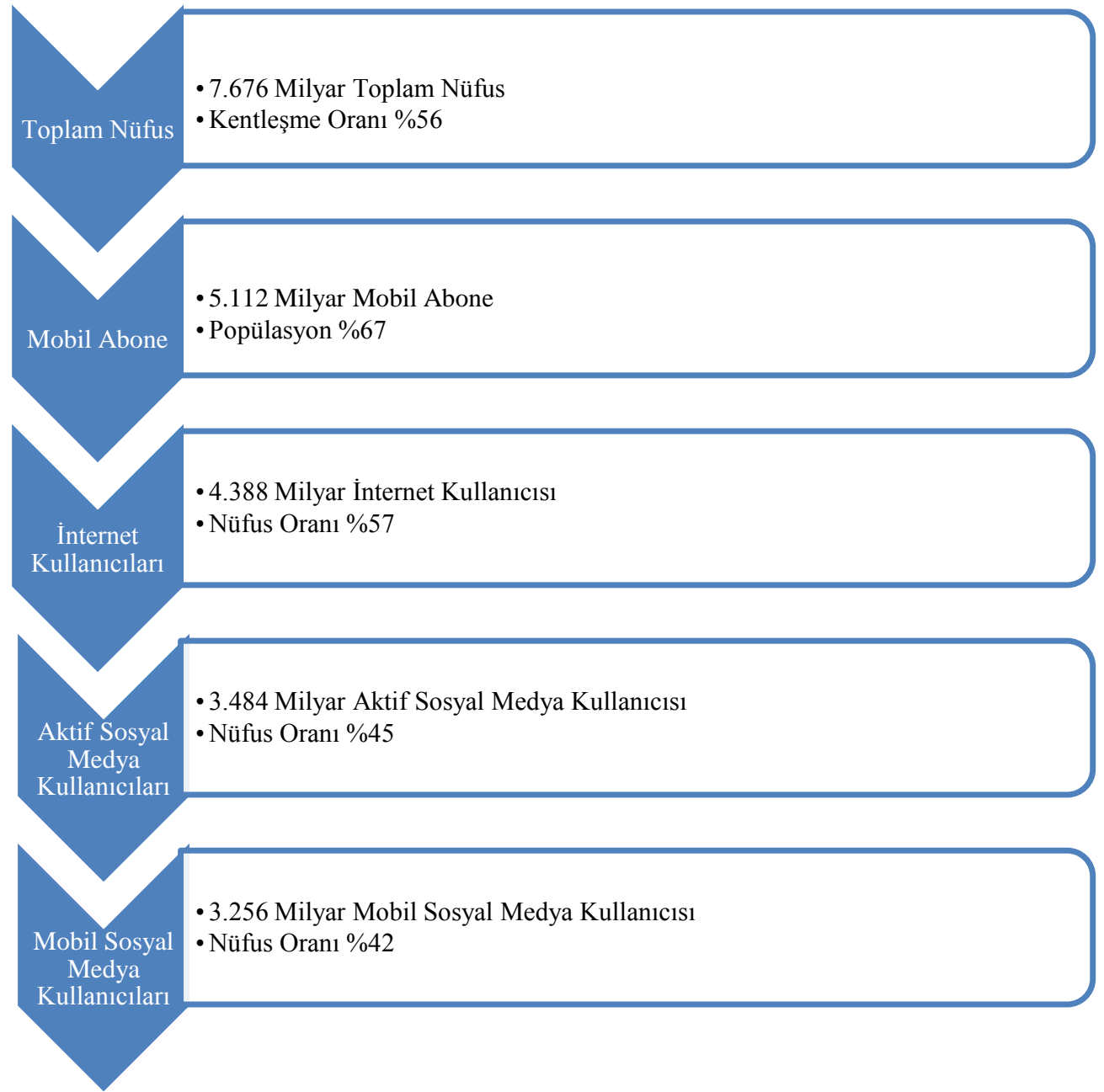

Şekil 1. 2019 küresel dijital raporu (dünyada mobil, internet ve sosyal medya kullanımı)

Kaynak: (https://www.motionb.com/blog/2019-turkiye-kuresel-dijital- raporu)

Şekil 1'de yer alan verilere göre küreselleşen Dünya'da dijitale yaklaşım ve yatkınlık ele alındığında 7,5 milyarı aşan dünya nüfusunun \% 57'lik bir kısmının interneti aktif olarak kullandığı görülmektedir. Yani, Dünyanın yarısından fazlası internet erişimine sahiptir. Dünya nüfusunun \%67'sinin mobil aboneliğe sahip olduğu görülmektedir ki, bu çok ciddi bir orandır. 
Diğer taraftan Dünya nüfusunun \% 45'inin sosyal medyayı (Facebook, Instagram, Twitter, Pinterest, Youtube, Tumblr, Snapchat, Linkedin vb. hesaplar) aktif olarak kullandığ 1 da raporda dikkat çeken bir başka ayrıntıdır. Bu oranlardan yola çıkarak bilgi paylaşımlarının da bu doğrultuda arttığı söylenebilir.

Bir diğer raporda ise Türkiye'de mobil abone, internet kullanıcıları ve sosyal medya kullanımına yönelik bilgiler verilmiştir. Şekil 2'de yer alan değerlendirmede, Türkiye'nin küreselleşen dünyada dijitalleşmeye olan uyumu hakkında bilgilere yer verilmiştir.

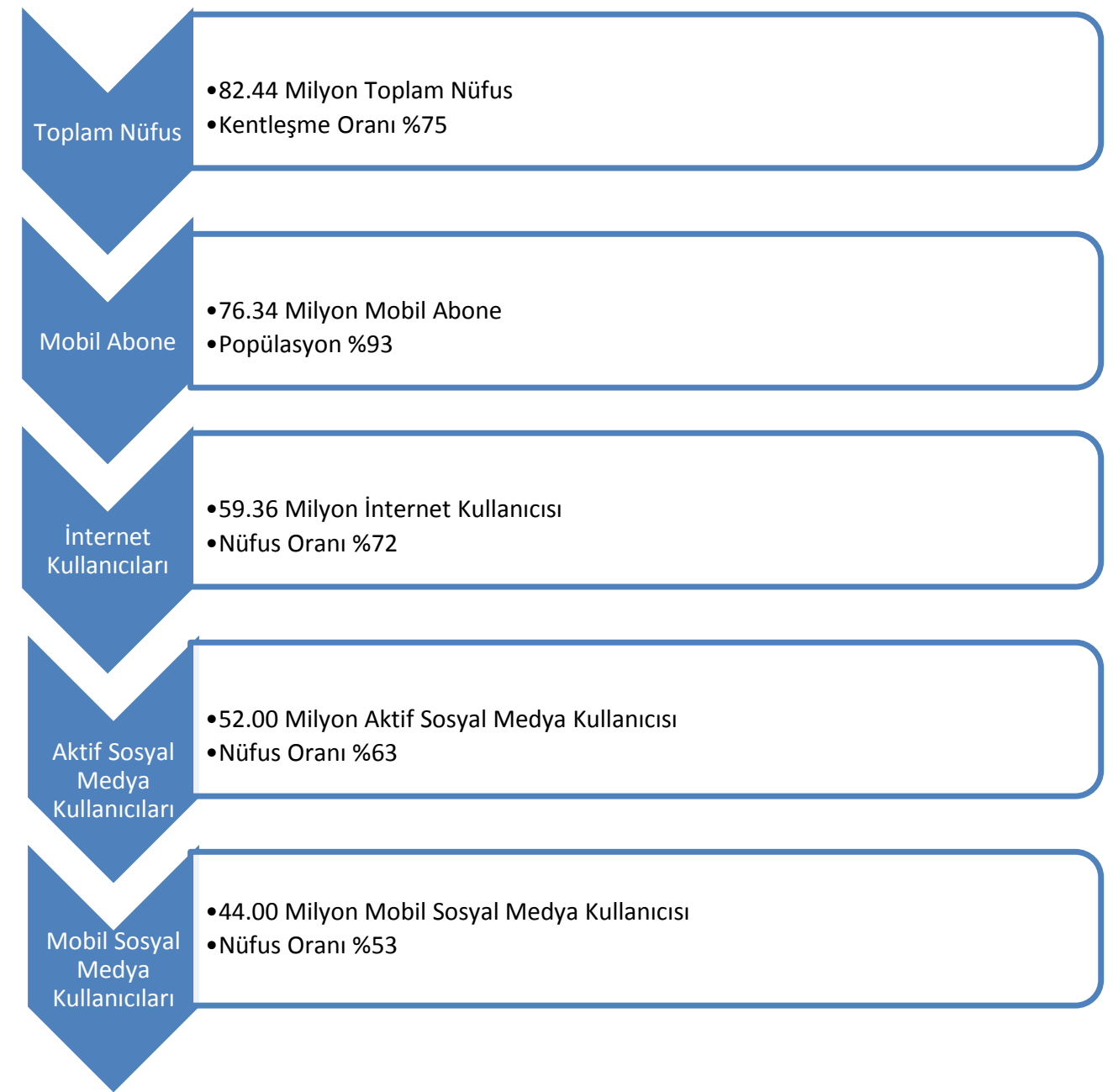

Şekil 2. 2019 küresel dijital raporu (mobil, internet ve sosyal medya türkiye değerlendirmesi)

Kaynak: (https://www.motionb.com/blog/2019-turkiye-kuresel-dijital- raporu)

Dünyada olduğu gibi Türkiye‘de de dijitalleşme oranının yüksek olduğu görülmektedir. Şekil 2'de yer alan raporda Türkiye nüfusu 80 milyonu aşmış durumdadır. Verilere göre, Türkiye'de internet kullanımı \% 72 gibi yüksek bir seviyeye ulaşmıştır. Nüfusun büyük bir kısmı internet kullanıcısı olarak etiketlenmiştir. Türkiye nüfusunun \% 63'ünün ise sosyal medya kullanıcısı olduğu görülmektedir. Nüfusun yarısından fazlasının sosyal medya 


\section{Ersöz, B. \& Kahraman, $\ddot{U}$. G.}

kullanıcısı olduğu ülkemizde, sosyal medya kullananların \% 53'ünün yani yine yarısından fazlasının mobil sosyal medya kullanmayı tercih ettiği görülmektedir. Türkiye'de mobil abone oranındaki \% 93 artış ise oldukça dikkat çekicidir.

Özetle, ülke nüfusunun 3/4'lük kısmı interneti aktif olarak kullanmaktadır. $\mathrm{Bu}$ verilerinden yola çıkarak, internetin kullanımının her yerde yaygınlaştığı söylenebilir. İşyerlerinde, evlerde, okullarda, kafelerde ve daha birçok alanda wifi ile bağlantı kurularak bilgiye tek bir işlemle ulaşılabilmektedir. Bireyler zamanlarının büyük çoğunluğunu dijital dünya ile bağlantılı bir şekilde geçirdiğinden, bilgiye erişim de o denli hızlı olmaktadır. 2019 yılına ait Dünya ve Türkiye'de yaşanan dijitalleşme süreci ile ilgili istatistikler doğrultusunda, bireylerin günlük hayatlarında aşırı bilgi yüklü bir yaşam sürdükleri söylenebilir. İnsanlar artık günümüzde bilgi-yoğun bir dünyada faaliyet göstermektedir (McCombs,2014). Öyle ki, teknolojinin var olduğu dünyanın her yerinde bireyler internet yoluyla istenilen zamanda bilgiye bir tık uzakta yaşamaktadır. Ancak, bilgiye olan açlık ne kadar fazla ise dijital dünyada karşılaşılan bilgi kirliliği de bir o kadar yüksektir. Bawden ve Robinson 2009 yılında aşırı bilgi yükü hakkında yapmış oldukları araştırmada, Web 2.0 teknolojilerinin bilgi kirliliğini daha da arttırdığı sonucuna ulaşmışlardır. Bu kirliliğin sebeplerinden biri sosyal medyadaki paylaşımların son yıllarda oldukça ivme kazanması ve bireyler arası çevrimiçi paylaşım yapma olanağının artmasıdır. Tüm bunlarla birlikte, infobezitenin artmasını tetikleyen bir diğer unsurda, dünya genelinde şirket içi müşteriler ve tedarikçiler ile iş iletişiminde genel bir artış bulunmasıdır. Bundan kaynaklı çalışanlar arasında daha fazla bilgi akışı gerekmektedir. Sürekli iletişim halinde kalma çabası içinde olan kurumlar telefon, sesli çağrılar, e-posta, internet ve çevrimiçi konferanslar yoluyla da iletişim kurarak bilgi yoğunluğunun oluşmasına neden olmaktadır.

Bir diğer bilgi fazlalığına yol açan etken ise akıllı telefonlardır. Son yıllarda, bireyler gündelik hayatlarında her türlü bilgiye erişmek için akıllı telefonlarını kullanmaya başlamışlardır. İnternet ağlarına bağlanabilen bu teknolojiler bireylerin her türlü bilgiye eriştiği ve anlık çevrimiçi mesajları gönderebildiği iletişim araçlarına dönüşmüştür. Bu durum mobil cihaz teknolojilerinin bireylerin günlük yaşamlarının ayrılmaz bir parçası haline gelmesini kaçınılmaz kılmıştır. Mobil cihazlara yüklenen çeşitli uygulamalardan gelen anlık bildirimler, internet tarayıcılarını her türlü bilgi için yoklama, iletişim araçlarına anlık gelen mesajlar ve emailler gibi uygulamalar bilgi istilasının daha da artmasına zemin hazırlamıştır. 
Bu çalışmanın devamında, bilişim çağının insanları maruz bıraktığı bilgi obezliğinin sebep olduğu yeni bir kavram olan infobeziteye neden olan teknolojiler üzerine yapılmış araştırmalara yer verilmişstir.

\section{WEB 2.0 TEKNOLOJILERININ İNFOBEZITE ETKİSI}

Web 2.0 terimini ilk kullanan Tim O’Reilly’e (2005) göre bu teknoloji, bilgisayar endüstrisinde internetin bir düzlem olarak ortaya çıkmasıyla birlikte bu düzlemin kurallarını anlamaya çalışan bir işletme devrimidir. Bu durumun başlıca kuralı; ağ etkilerini daha çok bireyin kullanabilmesi için programlar kurmaktır. Yani, ağın etkilerini daha çok bireyin kullanabilmesi için yeni programlar geliştirmektir. Web 2.0 teknolojilerinin gelişmesi ile birlikte wikiler, bloglar, çeşitli sosyal medya platformları gibi etkileşimli bilgi kaynakları ortaya çıkmıştır. Resim, video, müzik ve çeşitli dosya türleri web teknolojisi sayesinde bilgi akışını hızlandırmıştır. Özellikle iş dünyasının en önemli iletişim kaynakları arasında yer alan epostalar, en geniş bilgi akışı kullanım alanlarından birisidir. Kurumlar gerek müşteri gerek çalışan ile e-posta kullanımı sayesinde bilgiye erişimi oldukça hızlı ve kullanışlı hale getirmiştir. Ancak, e-posta adresleri her gün onlarca gereksiz bilgi ile dolmaktadır. Mano ve Mesch (2010) aşırı e-posta kullanımının performans üzerindeki istenmeyen etkileri üzerine yaptıkları çalışmada, aktif çalışma hayatının vazgeçilmezi olan e-postaların günlük bilgi alışverişine yön verirken, aynı zamanda spamların da bu iletişim aracını gereksiz bir sürü bilgi ile doldurduğunu söylemişlerdir. Gereksiz bilgiler, çalışanların dikkatini dağıtarak olumsuz etki yaratmakta ve performans düşüşüne sebep olmaktadır.

Bilgi kirliliğine maruz bırakan bir diğer platformda sosyal medyadır. Sosyal medyayı, ağ teknolojilerini kullanma yoluyla insanların diğerleriyle etkileşim kurmasına imkân tanıyan araç, hizmet ve uygulamaların bütünü şeklinde tanımlayan Boyd (2008) aynı zamanda sosyal medyayı "şemsiye bir terim" olarak nitelendirmektedir. Bireylerin anlık olarak bilgi akışı, içeriklere erişim ve haberleşmelerini sağlayarak bilgi bombardımanına sebebiyet veren bu platformda anlık bilgi akışları hızlı iken, bu bilgilerin doğruluğunu keşfetmek de o derece zordur. 


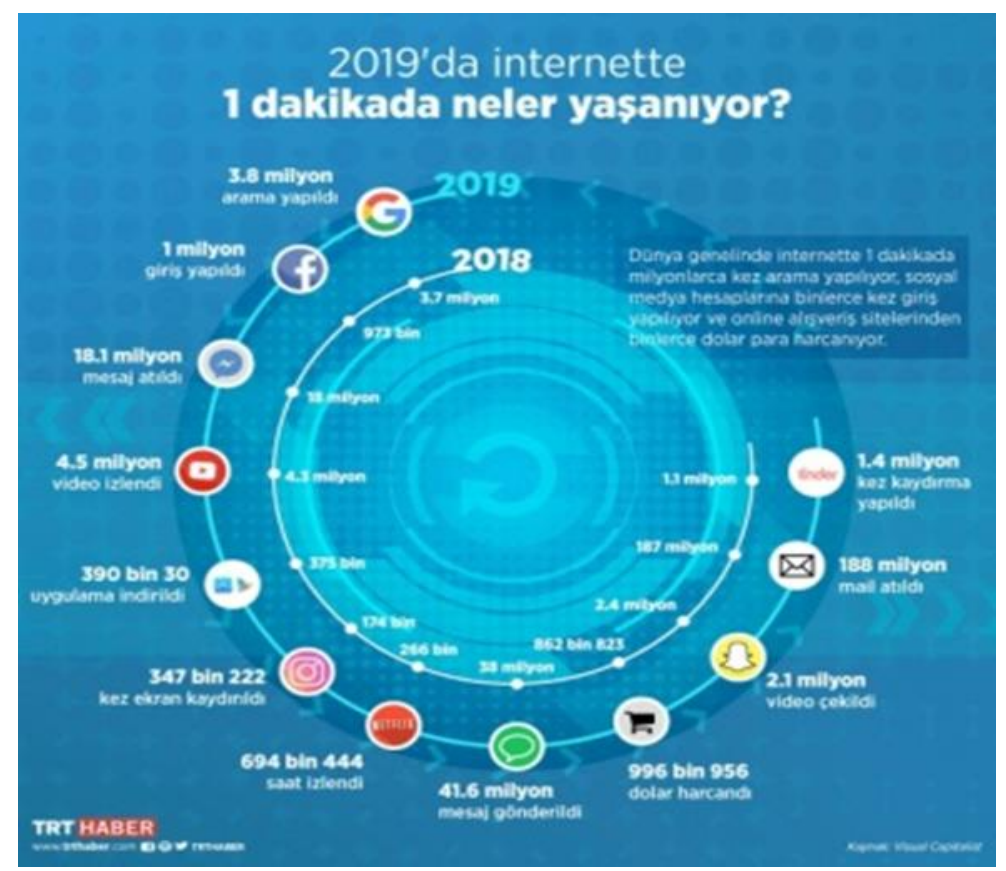

Şekil 2. 2019 yılında internette 1 dakikada yaşananlar

Kaynak: (www.trthaber.com/haber/dunya/2019da-internette-1-dakikada-neler-yasaniyor409609.html)

Şekil 3'de sosyal medya kullanımına ilişkin bilgiler yer almaktadır. Sosyal medya uzmanları Lewis ve Callahan (2019) tarafindan toplanan verilere göre 2019 yılında bireyler internet için daha fazla zaman ayırmakla kalmayıp, interneti kullanma alışkanlıklarını da değiştirdi. Aralarında Twitter ve Snapchat'in de bulunduğu sosyal medya devleri 2019 yılına 2018'e oranla düşüşle başlarken, uluslararası dizi ve film izleme platformu olan Netflix ve Instagram'da 2018 yılının aynı dönemine kıyasla 2019 yılında ciddi bir yükselme yaşadı. Instagram 2018 yılında 174 bin ekran kaydırma yaşarken, bu oran 2019 yılında yaklaşık iki katı bir artış göstererek 347 bin ekran kaydırma yaşamıştır. Facebook, uluslararası veri skandallarına rağmen, küçük yüzdelerde de olsa, aktif kullanıcı sayısını artırmaya devam etmiştir. Snapchat, 2018'in başlarında yeniden tasarlanmasından sonra kullanıcılarını kaybetmiştir. 2018 yılında insanlar internet üzerinden alışverişe 862 bin 823 dolar harcarken, 2019 yılında bu rakam 996 bin 956 dolara çıkmıştır. En çok bilgi akışının yapıldığı platformlardan birisi olan Whatsapp ise 39 milyondan, 41.6 milyona yükselerek mesajlaşmanın dramatik bir şekilde arttığı bir platforma dönüşmüştür. Video izleme platformları arasında yer alan youtube ise 2018 y1lında 4.3 milyon izleme oranına sahipken, 2019 y1lında bu oran 4.5 milyona yükselmiştir. Bu bilgiler doğrultusunda, 1 dakikada dünyada yaşanan bilgi akış1 oldukça fazladır. Verilerden yola çıkarak internet kullanımına bağlı Web 2.0 teknolojilerindeki bilgi akışının bir yılda bile şaşırtıcı derecede arttığı söylenebilir. 
Hızlı bilgi akışının olduğu bilişim çağında güvenilir veriyi elde etmek ise oldukça zordur. Sosyal medyanın bireyler üzerindeki etkisi ise oldukça fazladır. Dijitalleşmenin sonucu olarak süregelen sosyal medya, bireylerin yaşamlarının tam ortasında yer almaktadır. Anlık fotoğraf, yer bildirimleri ve günlük akışı bildiren bilgilerle bireylerin beyni dolup taşmaktadır. Anlık olarak güvenli-güvensiz ayrımı olmaksızın bilgi akışı yaşanmaktadır. Bireylerin maruz kaldıkları bu yoğun iletişim eylemleri, onların yararlı bilgi edinme ve kullanma şanslarını azaltmakta, karar verme süreçlerini etkilemektedir. Bundan dolayı doğru bilgiye ulaşmak için bilginin güvenliğinin sorgulanması gerekmektedir (Trthaber,2019).

Bu doğrultuda, 1996'da Web'in ilk dönemlerinde yayınlanan Reuters'in bilgi için ölüm raporunda Reuters tarafından özetlenen şaşırtıcı istatistiklerde Paul Waddington (1996) tarafından “İngiltere'de ve Dünyada Yüklenen Bilginin Etkileri” adlı çalışmasında ABD, Hong Kong ve Singapur'da 1.300 yönetici ile görüşülmüştür. İngiltere'den ise araştırmaya 500 kıdemli ve genç yönetici katılmıştır. Odak grup tekniği de çalışma sürecinin önemli bir parçasını oluşturmuştur. Ankete katılan yöneticilerin \% 38'i sadece bilgi aramak için önemli miktarda zaman harcadıklarını belirtmiştir. Dosyaların farklı yazılım formatlarında tutulması ve günün kritik saatlerinde internetin hızı gibi faktörler bu duruma sebebiyet vermiştir. Katılımcıların \% 43'ü, kararların ertelenmesine ve "analiz felci" ya da çok fazla bilginin varlığından olumsuz etkilenmesine rağmen, katılımcıların \% 47'si bilgi toplamanın kendilerini ana sorumluluklarından uzaklaştırdığını söylemiştir. Edinilen bilgilerle başa çıkmak için stratejiler geliştirmekte kişilerin zorlandığı görülmektedir. Tüm dikkat dağıtıcı unsurların kaldırılması durumunda üretkenlikteki potansiyel artışı hayal etmek mümkündür. Yapılan çalışma insan maliyetleri açısından, ilk kez aşırı bilgi yükünün strese katkıda bulunduğunu tespit etmiştir. Ankete katılanların her üç kişiden ikisi, bilgi yükünü meslektaşlarıyla gerginlik ve iş tatmini kaybı ile ilişkilendirmiştir. \% 42'si sağlıksızlığ bu strese bağlamıştır. \% 61'i aşırı bilgi yüklemesi sonucu sosyal faaliyetleri iptal etmek zorunda kaldığını, \% 60'1 ise boş zamanlarında etkinlik yapmak için çoğunlukla çok yorgun hissettiklerini belirtmiştir. ABD yöneticilerinin \% 39'undan fazlası İngiltere ve Hong Kong'dakilere göre daha fazla stres yaşadıklarını kabul etmektedir. Bireyler artık bilgiyi yönetmek için etkili kişisel stratejiler geliştirememektedir. Bilgi ve bilgi kanallarının saldırısıyla karşı karşıya kaldıklarında, bilgiyi yönetmek için basit rutinler gerçekleştirememektedir. Yöneticilerin üçte ikisi, aşırı bilgi yükü ile ilişkili stres nedeniyle iş arkadaşları ile gerilimin ve iş tatmini kaybının ortaya çıktığını belirtmektedir. Yöneticilerin üçte biri, aşırı bilgi yüklemesi ile ilişkili stresin doğrudan bir sonucu olarak sağlık sıkıntılarından muzdariptir. Bu rakam üst düzey yöneticiler arasında \% 


\section{Ersöz, B. \& Kahraman, $\ddot{U}$. G.}

43'e kadar yükselmektedir. Yöneticilerin neredeyse 3/2'si yani \% 62 si, aşırı bilgi yükü nedeniyle kişisel ilişkilerinin kötüleştiğini ifade etmektedir. Yöneticilerin \% 43'ü önemli kararların ertelendiğini ve çok fazla bilgiye sahip olduğunu düşünmektedir. Beş üst düzey yöneticiden biri bilgi toplamak ve aramak için önemli miktarda zaman harcandığını ifade etmektedir. Yöneticilerin neredeyse yarısı \% 48, internetin önümüzdeki iki yıl boyunca aşırı bilgi yüklemesinin başlıca nedeni olacağını düşünmektedir.

Bir diğer çalışma 2010 yılının başlarında bir araştırma şirketi olan Basex tarafından yapılan bir araştırmadır. Bu araştırmada bilgi çalışanlarının iş günlerini açıklamaya yönelik bir anket formu oluşturulmuştur. Basex'in yapmış olduğu çalışmanın bulguları şu şekildedir: Bilgi çalışanlarının \% 66'sı tüm işlerini yapmak için yeterli zamanları olmadığını düşünmektedir. Bilgi çalışanlarının \% 50'sinden fazlası günlük olarak kendilerine sunulan bilgi miktarının fazlalığının işlerini yapmadaki verimliliklerini düşürdüğünü belirtmiştir. Ankete katılanların büyük çoğunluğu \% 94'ü bilgi yetersizliği konusundaki bilgiler karşısında kendisini bunalmış hissetmektedir. Bilgi çalışanlarının \% 30'unun gün boyunca düşünmek için hiç zamanı olmamakla birlikte,\% 58'inin ise sadece 15 ile 30 dakika arasında bir süresi bulunmaktadır (Spira, 2011).

Jones vd. (2004) çalışmalarının sonuçlarına göre ise, çevrimiçi etkileşim ortamlarında aşırı bilgi yükü yaşayan bireylerin karmaşık mesajların aksine basit mesajlara yanıt verme ve üretme olasılıkları daha yüksektir. Ayrıca çalışanlar üzerinde yapılan başka bir çalışmada, işyerinde aşırı bilgi yükü yaşamanın temel nedenleri sorgulanmıştır. Buna cevap olarak çalışanlar, görevlerinin verimli ve etkili bir şekilde yerine getirilmesi için üzerlerine uygulanan baskının infobeziteye neden olduğunu belirtmiştir. Bu bulgu, aşırı bilgi yükü algılarını bireylerin yaşadığı zaman baskısı ile ilişkilendiren diğer çalışmalarla tutarlıdır (Kock, 2000). Çalışanların çok fazla bilgiye maruz kalmaları onların işlerine odaklanmada problem yaşamalarına sebep olmaktadır.

\section{AKILLI TELEFONLARIN INNFOBEZITE ETKISİ}

1980’li yıllara kadar insanların hayatlarında yer almayan cep telefonları, seri üretim ile birlikte kitle iletişim aracı haline gelmiştir. Telefonlar ilk çıktığında sadece bireyler arasında konuşmayı ve mesajlaşmayı sağlamaktaydı. İlk çıkan cep telefonları hem boyut hem işlevsellik olarak daha farklı fonksiyonlara sahipti. Antenler yardımı ile sinyallerin ulaştığı, daha büyük ancak işlevsellik olarak daha az işlemin yapılabildiği araçlardı. Her geçen sene farklı modeller 
ve versiyonları ile kendini güncelleyen cep telefonları, son yıllarda büyük bir dönüşüm geçirerek akıllı telefonlar olarak bireylerin hayatlarında yer edinmeye başladı. Akıllı telefonlara, onları sıradan cep telefonlarından ayıran birçok farklı özellik eklendi. Günümüzde akıllı telefonlar, wifi, mobil internet erişimi, bluetooth, uygulama indirme özellikleri ile çeşitli ofis yazılımları edinme, daha yüksek kapasiteli ekran ve ses sistemleri, e-posta gibi çeşitli özelliklere sahip bir donanım haline gelmiştir. Bu özelliklerin eklenmesi ile birlikte sadece konuşma ve kısa mesaj göndermek için kullanılan telefonun konumu günlük hayatta çok farklı bir yere sahip olmuştur. Eklenilen özellikler sayesinde akıllı telefonların günlük hayatta kullanım oranı artmış ve ceplerden düşmeyen bir teknoloji haline gelmiştir.

Türkiye İstatistik Kurumu (TÜİK), 16-74 yaş grubundaki bireylerin 2018 yılı Nisan ayı ile 2019 yılı Mart ayları arasındaki internet kullanımını ölçtüğü hane halkı bilişim teknolojileri kullanım araştırmasını yayınladı. Yapılan incelemede bireylerin internet kullanımı, evlerin ağa erişim imkânı üzerine bilgi vermektedir. 2019 yılında 16-74 yaş grubundaki bireylerde internet kullanımının geçen yıla göre yüzde 2,4 yükselerek yüzde 75,3 olduğu belirtiliyor. İnternet kullanım oranları erkeklerde yüzde 81,8 iken kadınlarda yüzde 68,9 oldu. Türkiye'deki hanelerin yüzde 88,3'ünün evden internete erişim imkânına sahip olduğu gözlendi (Medyascope, 2019). Bilgi ve İletişim İstatistik Kurumu'nun 2019 y1lı Mart ayı itibariyle açıkladığ1 sonuçlarda ise Türkiye'de yaklaşık \%98,7 penetrasyon oranına karşılık gelen, makineler arası iletişim (M2M) aboneleri dâhil, toplam 80.926.4812 mobil abone bulunmaktadır. Makineler arası iletişim 0-9 yaş arası hariç olmak üzere mobil penetrasyon oranı \%110,9 olarak gerçekleşmiştir. Araştırmalar, akıllı telefon kullanıcılarının çok çeşitli mobil uygulamalar kullanarak bilgi ile ilgili çeşitli etkinlikler gerçekleştirdiğini göstermektedir (Falaki vd., 2010; Barkhuus ve Polichar, 2011). Akıllı telefonlar artan kullanım oranı ve aşırı bilgi yükünün giderek yaygınlaşmasıyla birlikte bir sorun haline gelmiştir. Akıllı telefon kullanım sıklığının artması ile depresyon, stres ve kaygı bozukluğu gibi psikiyatrik rahatsızlıkların da arttığı görülmüştür (Karaaziz ve Keskindağ, 2015: 78).

Kamvar ve Baluja (2006) cep telefonu kullanımına yönelik yaptıkları araştırmada, büyük ölçekli bir mobil arama sorgusu günlük analizini yürütmüşlerdir. Yapmış oldukları çalışmada kullanıcıların cep telefonlarında Google üzerinden arama yaparken daha kısa sorgular girme ve nadiren gelişmiş arama kullanma eğiliminde olduklarını bulmuşlardır. Ayrıca, otuz iki arama motorunda yaklaşık altı milyon arama kaydının analizi yapılmış ve mobil sorguların sonucunda en önemli konuların yetişkinlere uygun içerik, işlemsel ve gezinme 


\section{Ersöz, B. \& Kahraman, $\ddot{U}$. G.}

olduğu keşfedilmiştir. Bilgi obezliğinin ortaya çıkardığı problemlerden yola çıkarak çeşitli araştırmalar yapılmıştır.

Sartori’nin de söylediği gibi “evrensel bir kütüphane olan internet” insanların kolaylıkla ve sınırsız verilere ulaşmalarına imkân tanır hale gelmiştir. Akıllı telefonlarda bu kütüphanelere erişimde başrolde yer alan infobezite araçları olarak yer edinmişlerdir. Yapılan analizler ve çalışmalara bakıldığında her geçen gün akıllı telefon kullanımına bağlı internet erişimi artmaya devam etmektedir. Dijitalleşmeye bağlı gidişat göz önünde bulundurulduğunda durumun daha da artarak devam edeceği söylenebilir.

\section{SONUÇLAR}

Dijital çağ ile birlikte ortaya çıkan bilgi fazlalığ günümüzde bilgi kirliliğine yol açmıştır. Doğru ve güvenilir bilgiye erişmek için harcanılan zaman oldukça fazladır. Bilginin bolluğunda boğulurken bireyleri esir alan bu yorgunluk doğru bilgiye erişmede eksik kalmaktadır. Gerek akıllı telefonlar gerekse bilgisayarlarla giriş yapılan sosyal medya platformlarında yer alan herhangi bir bilginin doğruluğu bilinmeden çeşitli kaynaklar aracılığıyla bireylere ulaşmaktadır. Üstelik çoğu bilgiler güvenilirliği test edilmeden gün içerisinde defalarca bireylerin karşılarına çıkmaktadır. Bilginin hızla yayıldığı bilişim çağında gerçek kaynağa erişene kadar doğru bilgiyi elde etmek olanaksız hale gelmiştir. Web 2.0 teknolojilerinden wikiler, bloglar, youtube, sosyal medya platformu vb. gibi çeşitli iş birliği etrafında toplanan sayfalar aracılığı ile gün içerisinde bilgi kaynaklarına milyonlarca bilgi yüklenmektedir. Bu platformlar kontrol edilemeyen bir bilgi gücü haline gelmiştir. Her geçen gün artan bu güç gelecek yıllarda da infobezitenin etkisini arttırarak yoluna devam edeceğini işaret etmektedir. Ayrıca gün içerisinde çalışanların e-posta kutuları çeşitli bilgiler ile dolup taşmaktadır. Tanıtım reklamları ve anlık gereksiz bilgi akışlarının sebep olduğu bu bilgi

obezliğgi çalışanların zihinlerinde karmaşaya sebep olmaktadır. İncelenmiş olunan araştırmalarda bu durum karşısında gerek ruhsal gerekse bedensel problemler ortaya çıkmaktadır.

Baş döndürücü bir hızla gelişen teknoloji ile birlikte ortaya çıkan bilgi obezitesi kavramı yani infobezite, bireylerin doğru bilgeye ulaşmasını engelleyen bir bilgi bombardımanıdır. Günümüzde bireylerin beyinleri Web 2.0 teknolojilerinin ve akıllı telefonların sebep olduğu birçok gereksiz bilgi ile dolarken, öğrenilmesi gerekilen asıl bilgiye aç kalabilmektedir. Web 2.0 teknolojilerinin dijital dünyaya sunduğu platfomlarda aramalar yapılırken ortaya çıkan 
farklı sonuçlar bireylerin hem zaman kaybı yaşamasına yol açmakta hem de karar vermelerini zorlaştırmaktadır. Bilginin gücünün keşfedildiği bilişim çağında hızla artan bu platformların, infobeziteyi daha da arttıracağı düşünülmektedir. Dijitalleşme ile bireylerin maruz kaldığı bu aşırı bilgi yükünü yok etmek ya da en doğru çözüm yolunu bulmak ise kolay değildir. İnfobezite bilişim teknolojilerinin getirdiği bir problem olmakla beraber, bilgi obezliğini azaltmakta yine bilişim çağının getirdiği teknolojilerden faydalanılabilir. Her geçen saniye artan bilgi obezliği faydalı bir hale dönüştürülmediği sürece bilgi kirliliğine sebep olmaya devam edecektir. Aşırı bilgi yükünden uzaklaşmak ve edinilen bilgileri faydalı hale dönüştürmek için veri madenciliği uygulamalarından faydalanılabilir. Çeşitli kurum içi veri analiz yöntemleri ya da uygulamaları geliştirilerek çözüm yolları bulunabilir. Kurumların geliştirdikleri stratejik yönetim modelleri çalışanlarının yüklendikleri bu bilgi istilasından korunmada yardımcı olabilir. Ayrıca bireylerin maruz kaldıkları bilgi yorgunluğunu azaltmada akıllı telefonların bildirim ayarlarının kapatılması ve internet erişiminin azaltılması gibi yöntemlerde bu problemin azalmasında kolaylık sağlayabilir. Son olarak bu çalışmada infobezite, yalnızca kavramsal boyutuyla ele alınmıştır. Konuyla ilgili yapılacak ileriki çalışmalarda nitel ve nicel araştırma yöntemleriyle de desteklenerek infobezite kavramının daha kapsamlı bir şekilde değerlendirilmesi gerekmektedir.

\section{REFERENCES / KAYNAKLAR}

Barkhuus, L. \& Polichar, V. E. (2011). Empowerment through seamfulness: Smart phones in everyday life. Personal and Ubiquitous Computing, 15(6), 629-639.

Bawden, D. \& Robinson, L. (2009). The dark side of information: Overload, anxiety and other paradoxes and pathologies. Journal of Information Science, 35(2), 180-191.

Beyond the Beginning: The Global Digital Library. Erişim tarihi: 10.05.2020, http://www.ukoln.ac.uk/services/papers/bl/.blri078/content/repor 13.htm

Boyd, D. (2008). Why youth (heart) social network sites: The role of networked publics in teenage social life. The John D. and Catherine T. MacArthur (Ed.), Youth, identity, and digital media (pp.2007-16) David Buckingham. Foundation Series on Digital Media and Learning, Cambridge: The MIT Press, MA.

Church, K., Smyth, B., Bradley, K. \& Cotter, P. (2008, September). A large scale study of European mobile search behaviour. In Proceedings of the 10th international conference on human computer interaction with mobile devices and services (pp. 13-22).

Clay Johnson, A.(2012). The information diet book. ABD: O’reilly Media.

Eppler, M. J. \& Mengis, J. (2008). The concept of information overload-a review of literature from organization science, accounting, marketing, mis, and related disciplines. In Kommunikationsmanagement im wandel (pp. 271305). Gabler. 


\section{Ersöz, B. \& Kahraman, $\ddot{U}$. G.}

Falaki, H., Mahajan, R., Kandula, S., Lymberopoulos, D., Govindan, R. \& Estrin, D. (2010, June). Diversity in smartphone usage. In Proceedings of the 8th international conference on mobile systems, applications, and services (pp. 179-194).

Geray, H. (2002). Illetişim ve teknoloji. Ankara: Ütopya Yayınları.

Hemp, P. (2009). Death by information overload. Harvard Business Review, 87(9), 82-9.

Jones, Q., Ravid, G. \& Rafaeli, S. (2004). Information overload and the message dynamics of online interaction spaces: A theoretical model and empirical exploration. Information Systems Research, 15(2), 194-210.

Karaaziz, M. \& Keskindağ, B. (2015). I love my smartphone: A review study of smartphone addiction and related psychological risk factors. Bağımlılık Dergisi, 16(2),78-85.

Kamvar, M. \& Baluja, S. (2006, April). A large scale study of wireless search behavior: Google mobile search. In Proceedings of the SIGCHI conference on Human Factors in computing systems (pp. 701-709).

Katz, E., Haas, H. \& Gurevitch, M. (1973). On the use of the mass media for important things. American Sociological Review, 38(2), 164-181.

Kock, N. (2000). Information overload and worker performance: A process-centered view. Knowledge and Process Management, 7(4), 256-264.

Korp, P. (2006). Health on the internet: Implications for health promotion. Health Education Research, 21(1), 7886.

Lewis E. (2018). The infobesity epidemic: How to avoid information overload. .Erişim tarihi: 05.05.2020, https://themultitaskingwoman.com/the-infobesity-epidemic-how-to-avoid-digital-overload/

Mano, R. S. \& Mesch, G. S. (2010). E-mail characteristics, work performance and distress. Computers in Human Behavior, 26(1), 61-69.

McCombs, M. E. (2014). The two w's of journalism: The why and what of public affairs reporting. UK: Routledge.

Medyascopetv. Erişim tarihi: 03.05.2020, https://medyascope.tv/2019/08/27/tuik-arastirmasina-gore-turkiyedeinternet-kullanim-orani-yuzde-753/

Naisbitt, J. (1982). Megatrends. New York: Charles Scribner's.

O’reilly, T. (2005). What is web 2.0. ABD: O'reilly Media.

Spira, J. B. (2011). Overload!: How too much information is hazardous to your organization. ABD: John Wiley \& Sons.

Toffler, A. (1970). Future Shock. New York, ABD: Bantam Books.

TRT Haber (2019). Erişim tarihi: 01.05.2020, https://www.trthaber.com/haber/dunya/2019da-internette-1dakikada-neler-yasaniyor-409609.html

We Are Social ve HootSuite (2019). Erişim tarihi, 05.05.2020, https://www.motionb.com/blog/2019-turkiyekuresel-dijital-raporu 